\title{
Flexible Polymer Photovoltaic Devices Prepared With Inverted Structures on Metal Foils
}

\author{
Fang-Chung Chen, Jyh-Lih Wu, Chia-Ling Lee, Wen-Che Huang, Huang-Ming Philips Chen, and Wen-Chang Chen
}

\begin{abstract}
We have prepared top-illuminated organic photovoltaic devices on stainless-steel substrates, using molybdenum trioxide/indium tin oxide as the transparent top electrode. Incorporating an $\mathrm{Al}$ counter electrode grid having a shadow fraction of $10 \%$ effectively reduced the device resistance, thereby enhancing the power conversion efficiency to ca. 3\%. This device exhibited superior mechanical flexibility. The inverted device architecture eliminated the need to use low-work-function metals, which are air sensitive and easily oxidized, thereby improving the air stability of the flexible devices.
\end{abstract}

Index Terms-Energy resources, flexible structures, photovoltaic cells, polymers.

\section{INTRODUCTION}

$\mathbf{O}$ RGANIC photovoltaic devices (OPVs) are promising alternatives to their inorganic counterparts for applications in portable consumer electronic devices because they offer the advantages of low fabrication costs, light weight, and fabrication at low temperature [1], [2]. More importantly, the mechanical flexibility of organic materials facilitates the preparation of OPVs using roll-to-roll and large-area processing on flexible substrates, thereby realizing fully flexible solar cells [3]-[5]. Most of the flexible OPVs reported to date have been fabricated on plastic substrates, such as polyethylene terephthalate [3][5]. On the other hand, metal foils are also receiving a great deal of attention in the field of flexible electronics because of their excellent mechanical flexibility, robustness, and thermal stability. They also provide the devices with effective protection against penetrating moisture and oxygen [6]-[10]. However, realizing flexible OPVs fabricated on opaque metal foils requires the development of top-illuminated devices [11], [12] featuring transparent top electrodes. In this letter, we prepared topilluminated OPVs possessing an inverted device architecture [13], [14], in which the electrons were collected by the bottom contact—indium tin oxide (ITO)/cesium carbonate $\left(\mathrm{Cs}_{2} \mathrm{CO}_{3}\right)$

Manuscript received March 26, 2009; revised April 20, 2009. First published June 10, 2009; current version published June 26, 2009. This work was supported in part by the National Science Council under Grant NSC 97-ET7-009-004-ET, by the Ministry of Economic Affairs under Grant 97-EC-17-A08-S1-015, and by the Ministry of Education through the ATU plan. The review of this letter was arranged by Editor P. K.-L. Yu.

F.-C. Chen, C.-L. Lee, W.-C. Huang, and H.-M. P. Chen are with the Department of Photonics and the Display Institute, National Chiao Tung University, Hsinchu 30010, Taiwan (e-mail: fcchen@mail.nctu.edu.tw).

J.-L. Wu is with the Department of Photonics and the Institute of Electrooptical Engineering, National Chiao Tung University, Hsinchu 30010, Taiwan.

W.-C. Chen is with the Institute of Polymer Science and Engineering, National Taiwan University, Taipei 106, Taiwan.

Color versions of one or more of the figures in this letter are available online at http://ieeexplore.ieee.org.

Digital Object Identifier 10.1109/LED.2009.2022345

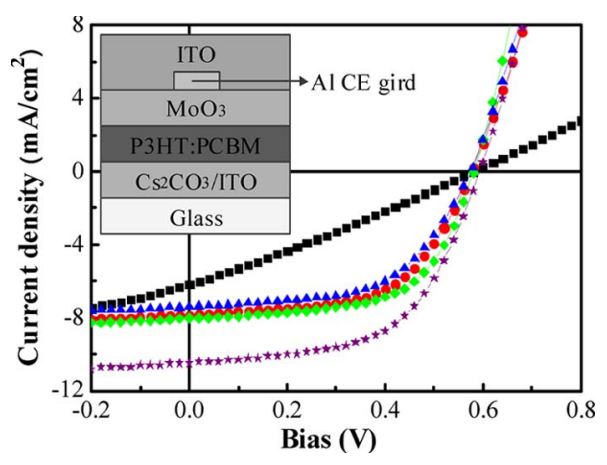

Fig. 1. Current density $(J)$-voltage $(V)$ characteristics, recorded under AM $1.5 \mathrm{G}$ illumination at $100 \mathrm{~mW} / \mathrm{cm}^{2}$, of top-illuminated OPVs on glass substrates incorporating $\mathrm{Al} \mathrm{CE}$ grids of various shadow fractions: (ם) No CE grid, $(\bullet) 5 \% \mathrm{CE}$ grid, $(\bullet) 10 \% \mathrm{CE}$ grid, $(\boldsymbol{\Delta}) 15 \% \mathrm{CE}$ grid, and $(\star) 10 \% \mathrm{CE}$ grid with an $\mathrm{Ag}$ mirror placed behind the device. (Inset) Schematic representation of the device structure.

[13], [14] and holes were collected by the top contactmolybdenum trioxide $\left(\mathrm{MoO}_{3}\right) / \mathrm{ITO}$. To further reduce the sheet resistance $\left(R_{\mathrm{sh}}\right)$ of the transparent top contact, $\mathrm{Al}$ counter electrode (CE) grids [15] were inserted between the $\mathrm{MoO}_{3}$ and ITO layers. With this configuration, we realized flexible devices on stainless-steel (SS) substrates; these OPVs exhibited excellent power conversion efficiencies (PCEs; ca. 3\%) in conjunction with superior mechanical flexibility and air stability.

\section{EXPERIMENT}

The inset to Fig. 1 provides a schematic representation of the device structure of a top-illuminated OPV on a glass substrate. To fabricate such a device, a solution of $\mathrm{Cs}_{2} \mathrm{CO}_{3}$ in 2-ethoxyethanol was spin-coated onto an ITO-coated glass substrate (ca. 8.7 $\Omega / \square$ ) to form the bottom contact, which was thermally annealed at $150{ }^{\circ} \mathrm{C}$ for $15 \mathrm{~min}$ [14]. The photoactive layer, which is a solution of poly(3-hexylthiophene) (P3HT) and $[6,6]$-phenyl- $\mathrm{C}_{61}$-butyric acid methyl ester (PCBM; $1: 1$, $\mathrm{w} / \mathrm{w}$ ) in 1, 2-dichlorobenzene (DCB), was deposited on top of the $\mathrm{Cs}_{2} \mathrm{CO}_{3}$ layer. The wet film was transferred to a Petri dish and subjected to solvent annealing for at least $2 \mathrm{~h} \mathrm{[2];}$ the dried films were then thermally annealed at $110{ }^{\circ} \mathrm{C}$ for $15 \mathrm{~min}$. The transparent top contact comprised 15-nm-thick $\mathrm{MoO}_{3}$ and 160-nm-thick ITO layers. To reduce the value of $R_{\mathrm{sh}}$ of the top electrode, 100-nm-thick Al CE grids prepared with various shadow fractions $(5 \%, 10 \%$, and $15 \%)$ were inserted between the $\mathrm{MoO}_{3}$ and ITO layers. The top ITO film was deposited through RF sputtering under an $\mathrm{Ar}$ atmosphere. The $\mathrm{MoO}_{3}$ layer and $\mathrm{Al} \mathrm{CE}$ grids were deposited through thermal 


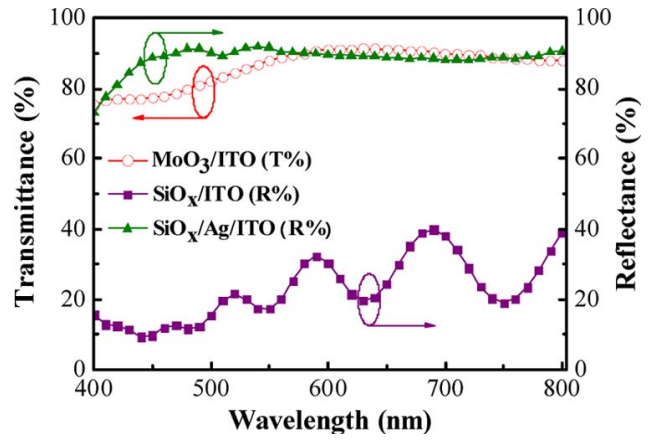

Fig. 2. Transmittance spectrum of the transparent top contact $\left(\mathrm{MoO}_{3} / \mathrm{ITO}\right)$ and reflectance spectra of the bottom contacts (with and without $\mathrm{Ag}$ ) of flexible OPVs fabricated on SS substrates.

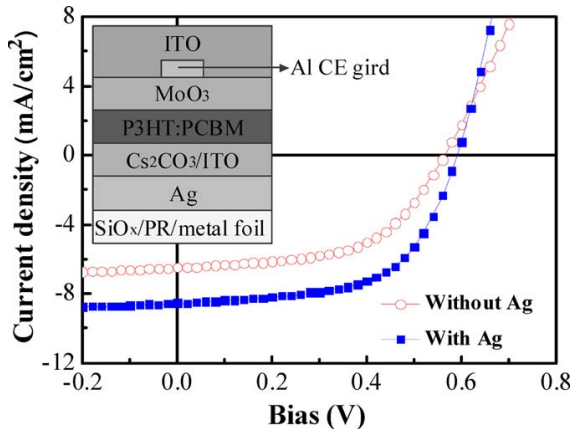

Fig. 3. $J-V$ characteristics of flexible OPVs on metal foils, prepared with and without a bottom Ag layer. (Inset) Schematic representation of the device structure of the flexible OPVs.

evaporation under a vacuum of ca. $3 \times 10^{-6}$ torr. The device area, defined through a shadow mask, was $0.12 \mathrm{~cm}^{2}$. Finally, the completed devices were postannealed at $140{ }^{\circ} \mathrm{C}$ for $5 \mathrm{~min}$ in a glove box. Fig. 2 shows the transmittance spectrum of the transparent top contact $\left(\mathrm{MoO}_{3} / \mathrm{ITO}\right)$. The average transmittance from 400 to $800 \mathrm{~nm}$ was $86.2 \%$, revealing that light was indeed transmitted efficiently through the top electrode. To fabricate flexible OPVs on SS substrates, a thick photoresist (PR) layer was first spin-coated to planarize the surface of the SS foils (inset of Fig. 3). After such treatment, the surface root-mean-square roughness decreased from 25.7 to $4.1 \mathrm{~nm}$, as measured using atomic force microscopy. A 100-nm-thick $\mathrm{SiO}_{x}$ layer was then deposited through electron beam evaporation to minimize any washing effect occurring during the subsequent wet processing. On top of the $\mathrm{SiO}_{x}$ layer, 100-nm-thick Ag and 100-nm-thick ITO layers were thermally evaporated and RF sputtered, respectively. The remaining fabrication procedures were identical to those used to prepare the devices on the glass substrates. Note that the Ag layer not only functioned as an optical reflector but also effectively reduced the value of $R_{\mathrm{sh}}$ of the bottom electrode. The current density-voltage $(J-V)$ characteristics of the OPVs were measured using a Keithley 2400 source measure unit. The photocurrent response was measured under the illumination provided by a $150-\mathrm{W}$ Thermal Oriel solar simulator equipped with AM1.5G filters. The illumination intensity was calibrated using a Si photodiode equipped with a KG-5 filter (Hamamatsu, Inc.) [16]. The transmittance and reflectance spectra were recorded using a Perkin-Elmer Lamda
950 spectrometer. The sheet resistances were determined using the four-point probe method.

\section{RESUlTS AND DISCUSSION}

Fig. 1 shows the $J-V$ characteristics, recorded under AM $1.5 \mathrm{G}$ illumination at $100 \mathrm{~mW} / \mathrm{cm}^{2}$, of the top-illuminated OPVs on glass substrates, featuring Al CE grids with different shadow fractions. For the device having the structure ITO/ $\mathrm{Cs}_{2} \mathrm{CO}_{3} / \mathrm{P} 3 \mathrm{HT}: \mathrm{PCBM} / \mathrm{MoO}_{3} / \mathrm{ITO}$ (i.e., the reference cell), the open circuit voltage $\left(V_{\mathrm{oc}}\right)$, short circuit current $\left(J_{\mathrm{sc}}\right)$, and fill factor (FF) were $0.59 \mathrm{~V}, 6.04 \mathrm{~mA} / \mathrm{cm}^{2}$, and 0.27 , respectively; the calculated PCE was $0.96 \%$. The series resistance $\left(R_{s}\right)$ for the reference cell, extracted from the inverse slope of the dark $J-V$ curve at a voltage of $1.5 \mathrm{~V}$ [17], was $64.5 \Omega \cdot \mathrm{cm}^{2}$. Apparently, the high $R_{\mathrm{sh}}$ of the $\mathrm{MoO}_{3} /$ ITO top electrode (ca. $100 \Omega / \square$ ) led to a low photocurrent and poor FF. To reduce the device resistance, we embedded $\mathrm{Al} \mathrm{CE}$ grids between the $\mathrm{MoO}_{3}$ and ITO layers (inset of Fig. 1). For the devices containing $\mathrm{Al} \mathrm{CE}$ grids featuring 5\%,10\%, and $15 \%$ shadow fractions, the values of $R_{s}$ were 7.6, 5.2, and $4.9 \Omega \cdot \mathrm{cm}^{2}$, respectively. Optimizing the shadow fraction of the CE grids is necessary for top-illuminated devices because the grids block part of the incoming light. For example, the compromised shadow fraction of the Al CE grid in Fig. 1 is $10 \%$; this top-illuminated OPV exhibited a remarkable PCE of $2.8 \%\left(V_{\mathrm{oc}}=0.59 \mathrm{~V} ; J_{\mathrm{sc}}=8.06 \mathrm{~mA} / \mathrm{cm}^{2} ; \mathrm{FF}=0.59\right)$, which is one of the best values for a semitransparent OPV measured under illumination from the top electrode. The PCE of the device was further improved to $3.51 \%$ after placing an $\mathrm{Ag}$ mirror behind the device (Fig. 1), indicating that optical loss through the semitransparent device could be minimized through light recycling. Because this high PCE is comparable with that of conventional bottom-illuminated devices (ca. 3.8\%), we deduced that optical loss, rather than the electrical properties, was the major limitation of the semitransparent device.

Next, we applied the transparent top electrode in the fabrication of flexible devices on SS substrates (inset of Fig. 3) having the following structure: SS foil/PR $/ \mathrm{SiO}_{x} / \mathrm{Ag} / \mathrm{ITO} /$ $\mathrm{Cs}_{2} \mathrm{CO}_{3} / \mathrm{P} 3 \mathrm{HT}: \mathrm{PCBM} / \mathrm{MoO}_{3} / \mathrm{Al} \mathrm{CE}$ grid (10\%)/ITO. Fig. 3 shows the corresponding $J-V$ curves, recorded under AM $1.5 \mathrm{G}$ illumination at $100 \mathrm{~mW} / \mathrm{cm}^{2}$, of the devices prepared with and without the Ag layer. We see that the bottom $\mathrm{Ag}$ layer played a crucial role in determining the device performance. The $\mathrm{Ag}$ layer reduced the value of $R_{\mathrm{sh}}$ of the bottom contact from 130 (without $\mathrm{Ag}$ ) to $0.3 \Omega / \square$ (with $\mathrm{Ag}$ ), thereby decreasing the value of $R_{s}$ of the device from 9.1 to $3.3 \Omega \cdot \mathrm{cm}^{2}$ and increasing the FF from 0.55 to 0.59 . The bottom Ag layer also acted as an efficient optical reflector, leading to a marked enhancement in reflectance at the bottom contact (up to ca. $90 \%$ in the visible region; Fig. 2). As a result, the value of $J_{\mathrm{sc}}$ increased notably from 6.48 to $8.51 \mathrm{~mA} / \mathrm{cm}^{2}$, and the value of $V_{\text {oc }}$ increased slightly from 0.57 to $0.59 \mathrm{~V}$. Overall, the calculated PCE of the flexible OPVs improved from $2.02 \%$ to $2.97 \%$ after incorporating the Ag layer.

To examine the mechanical stability of the flexible OPVs, we performed a cyclic bending test at a radius of $0.8 \mathrm{~cm}$ under 


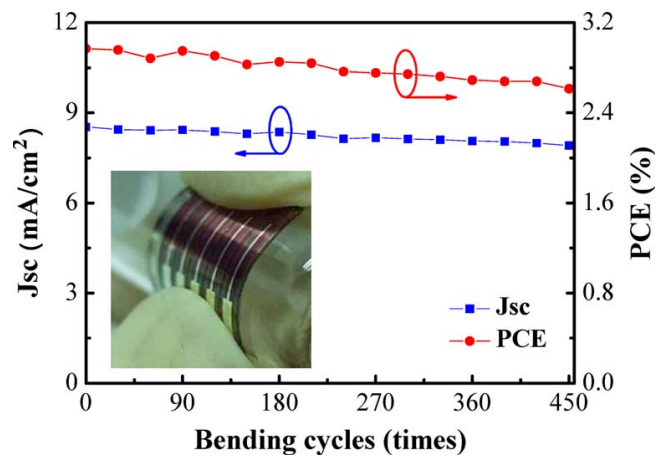

Fig. 4. Plots of $J_{\mathrm{sc}}$ and PCE with respect to the number of bending cycles (bending radius: ca. $0.8 \mathrm{~cm}$ ). (Inset) Photograph of the flexible OPVs prepared on metal foil.

ambient conditions. All the tested devices were unencapsulated during the testing. Fig. 4 shows that the values of $J_{\mathrm{sc}}$ and PCE declined slightly-from $8.51 \mathrm{~mA} / \mathrm{cm}^{2}$ and $2.97 \%$ to $7.91 \mathrm{~mA} / \mathrm{cm}^{2}$ and $2.61 \%$, respectively-after 450 bending cycles, whereas the value of $V_{\text {oc }}$ remained relatively unchanged (from 0.59 to $0.57 \mathrm{~V}$ ). This trivial degradation in performance reveals that the device exhibited superior mechanical flexibility. To determine the possible reasons for the failure of the mechanical flexibility, we measured the change in $R_{\mathrm{sh}}$ of the bottom contact (Ag/ITO). The fractional increase in the sheet resistance $\left(\Delta R_{\mathrm{sh}} / R_{\mathrm{sh}}\right)$ after 450 bending cycles was only $3 \%$, i.e., the value of $R_{\mathrm{sh}}$ remained relatively unchanged, resulting in superior mechanical flexibility. Therefore, the slight degradation in the device performance that we observed during the bending test may have been due to fatigue of the top electrode (the change in resistance of which we were unable to measure at present) and/or of the interfaces between the organic layer and the buffer layers.

As a measure of the air stability, we found that the PCE remained at ca. $60 \%$ of its initial value (i.e., decreasing from $2.97 \%$ to $1.83 \%$ ) after storing the unencapsulated device, without bending, for 60 days. The inverted device architecture eliminated the need to use low-work-function metals, which are air sensitive and easily oxidized, thereby improving the air stability of the flexible OPVs [14], [18], [19].

\section{CONCLUSION}

In this letter, we have prepared top-illuminated OPVs possessing inverted structures on metal foils. The flexible OPVs prepared on SS substrates exhibited excellent mechanical flexibility and high air stability. In addition, flexible OPVs fabricated on metal foils achieved excellent PCEs of ca. $3 \%$.

\section{REFERENCES}

[1] C. J. Brabec, N. S. Sariciftci, and J. C. Hummelen, "Plastic solar cells," Adv. Funct. Mater, vol. 11, no. 1, pp. 15-26, Feb. 2001

[2] G. Li, V. Shrotriya, J. S. Huang, Y. Yao, T. Moriarty, K. Emery, and Y. Yang, "High-efficiency solution processable polymer photovoltaic cells by self-organization of polymer blends," Nat. Mater., vol. 4, no. 11, pp. 864-868, Nov. 2005.

[3] S. I. Na, S. S. Kim, J. Jo, and D. Y. Kim, "Efficient and flexible ITO-free organic solar cells using highly conductive polymer anodes," Adv. Mater. vol. 20 , no. 21 , pp. $4061-4067$, Nov. 2008

[4] G. P. Kushto, W. H. Kim, and Z. H. Kafafi, "Flexible organic photovoltaics using conducting polymer electrodes," Appl. Phys. Lett., vol. 86, no. 9, p. 093502 , Feb. 2005.

[5] Y. H. Zhou, F. L. Zhang, K. Tvingstedt, S. Barrau, F. H. Li, W. J. Tian, and O. Inganas, "Investigation on polymer anode design for flexible polymer solar cells," Appl. Phys. Lett., vol. 92, no. 23, p. 233308 , Jun. 2008.

[6] J. H. Cheon, J. H. Choi, J. H. Hur, J. Jang, H. S. Shin, J. K. Jeong, Y. G. Mo, and H. K. Chung, "Active-matrix OLED on bendable metal foil," IEEE Trans. Electron Devices, vol. 53, no. 5, pp. 1273-1276, May 2006.

[7] T. K. Chuang, M. Troccoli, P. C. Kuo, A. Jamshidi-Roudbari, M. K. Hatalis, I. Biaggio, and A. T. Voutsas, "Top-emitting 230 dots/in. active-matrix polymer light-emitting diode displays on flexible metal foil substrates," Appl. Phys. Lett., vol. 90, no. 15, p. 151 114, Apr. 2007.

[8] J. K. Jeong, D. U. Jin, H. S. Shin, H. J. Lee, M. Kim, T. K. Ahn, J. Lee, Y. G. Mo, and H. K. Chung, "Flexible full-color AMOLED on ultrathin metal foil," IEEE Electron Device Lett., vol. 28, no. 5, pp. 389-391, May 2007.

[9] C. C. Wu, S. D. Theiss, G. Gu, M. H. Lu, J. C. Sturm, S. Wagner, and S. R. Forrest, "Integration of organic LEDs and amorphous Si TFTs onto flexible and lightweight metal foil substrates," IEEE Electron Device Lett., vol. 18 , no. 12 , pp. 609-612, Dec. 1997.

[10] Z. Y. Xie, L. S. Hung, and F. R. Zhu, "A flexible top-emitting organic light-emitting diode on steel foil," Chem. Phys. Lett., vol. 381, no. 5/6, pp. 691-696, Nov. 2003.

[11] T. Oyamada, Y. Sugawara, Y. Terao, H. Sasabe, and C. Adachi, "Top lightharvesting organic solar cell using ultrathin $\mathrm{Ag} / \mathrm{MgAg}$ layer as anode," Jpn. J. Appl. Phys., vol. 46, no. 4A, pp. 1734-1735, Apr. 2007.

[12] X. R. Tong, R. F. Bailey-Salzman, G. D. Wei, and S. R. Forrest, "Inverted small molecule organic photovoltaic cells on reflective substrates," Appl. Phys. Lett., vol. 93, no. 17, p. 173 304, Oct. 2008.

[13] L. M. Chen, Z. Hong, G. Li, and Y. Yang, "Recent progress in polymer solar cells: Manipulation of polymer:fullerene morphology and the formation of efficient inverted polymer solar cells," Adv. Mater, vol. 21, no. 14/15, pp. 1434-1449, Apr. 2009.

[14] H. H. Liao, L. M. Chen, Z. Xu, G. Li, and Y. Yang, "Highly efficient inverted polymer solar cell by low temperature annealing of $\mathrm{Cs}_{2} \mathrm{CO}_{3}$ interlayer," Appl. Phys. Lett., vol. 92, no. 17, p. 173 303, Apr. 2008.

[15] F. C. Chen, J. L. Wu, K. H. Hsieh, W. C. Chen, and S. W. Lee, "Polymer photovoltaic devices with highly transparent cathodes," Org. Electron., vol. 9, no. 6, pp. 1132-1135, Dec. 2008.

[16] V. Shrotriya, G. Li, Y. Yao, T. Moriarty, K. Emery, and Y. Yang, "Accurate measurement and characterization of organic solar cells," Adv. Funct. Mater, vol. 16, no. 15, pp. 2016-2023, Oct. 2006.

[17] H. L. Yip, S. K. Hau, N. S. Baek, and A. K. Y. Jen, "Self-assembled monolayer modified $\mathrm{ZnO} /$ metal bilayer cathodes for polymer/fullerene bulkheterojunction solar cells," Appl. Phys. Lett., vol. 92, no. 19, p. 193313 , May 2008.

[18] S. K. Hau, H. L. Yip, N. S. Baek, J. Y. Zou, K. O’Malley, and A. K. Y. Jen, "Air-stable inverted flexible polymer solar cells using zinc oxide nanoparticles as an electron selective layer," Appl. Phys. Lett., vol. 92 , no. 25 , p. 253301 , Jun. 2008.

[19] M. S. White, D. C. Olson, S. E. Shaheen, N. Kopidakis, and D. S. Ginley, "Inverted bulk-heterojunction organic photovoltaic device using a solution-derived $\mathrm{ZnO}$ underlayer," Appl. Phys. Lett., vol. 89, no. 14, p. 143517 , Oct. 2006. 